\title{
37. The Way to Overcome the Difficulty in Re-Os Dating of Molybdenite
}

\author{
By Katsuhiko SuzuKI and Akimasa MasudA \\ Department of Chemistry, Faculty of Science, \\ The University of Tokyo, Hongo, Tokyo 113
}

(Communicated by Kazuo Yamasaki, M. J. A., Nov. 9, 1990)

\begin{abstract}
When a molybdenite was dissolved and treated by the conventional chemical procedure, it was difficult to achieve the isotopic equilibrium between the ${ }^{18 \tau} \mathrm{Os}$ radiogenically accumulated in the molybdenite and "common" Os added as a kind of internal standard, even after chemically complete decomposition. It is evident that this isotopic disequilibrium effect results in deterioration of Re-Os age for the molybdenite. A newly developed analytical technique employing a microwave digestion was found out to promote the isotopic equilibration of Os from two sources and to provide us with the ages concordant with those obtained by other geochronometers.
\end{abstract}

Key words: Re-Os chronometer; molybdenite; Os isotope disequilibrium; microwave digester.

The nuclide ${ }^{187} \mathrm{Re}$ decays to stable ${ }^{187} \mathrm{Os}$ through $\beta^{- \text {-decay }}$ with the half life of $4.23 \times 10^{10}$ years. ${ }^{1)}$ Since Re and Os belong to chalco- or sidero-phile group of elements, Re-Os geochronometer has been thought to be a promising technique for dating of sulfide minerals. Note that the formation ages of sulfide minerals cannot be easily obtained by other geochronometers. Among sulfide minerals, molybdenite is the most suitable for Re-Os dating, because Re abundance is high in molybdenite compared with other sulfides. However, analytical difficulty in determination of Os has hindered the popular use of this chronometer for a long time.

Osmium can easily escape as osmium tetraoxide even under the weakly oxidative circumstances. Accordingly, for the precise determination of Os concentration, great care is required during the procedure. In our study, several methods were tried, employing inductively coupled plasma source mass spectrometer (ICP-MS), Plasma Quad, VG Elemental Ltd., to measure the isotopic composition of Os.

Luck and Allègre'2) decomposed the molybdenite by $\mathrm{HF}$ and $\mathrm{HNO}_{3}$ with simple heating and finally determined the ${ }^{187} \mathrm{Os}$ content for the first time by means of isotope dilution using mass spectrometry. However, there remain problems in their method, because some of the molybdenites they analyzed show strange dates, for example, the dates older than the age of the earth. We also tried their method several times, but in vain. Little Os could be recovered following their procedure. Probably Os escapes during drying-up stage after the addition of hydrazine, which is used for reduction of $\mathrm{OsO}_{4}$ in their procedure.

We devised another method. To prevent loss of Os during decomposition, molybdenite is decomposed by nitric acid in a closed glass ampoule with keeping it in a water bath at about $80^{\circ} \mathrm{C}$ for one week. (Prior to decomposition by $\mathrm{HNO}_{3}$, a known amount of common $\mathrm{Os}$ as an internal isotopic standard is 
added to the pulverized molybdenite.) After decomposition, the precipitate of oxo-molybdenum acid formed is dissolved with ammonia solution and added to the sample solution. Then, Os is separated by distillation. To reduce the loss of Os due to the acid co-distilled into the trapping solution, the trap is exchanged every one hour.

It was found that the closed-ampoule acid decomposition resulted in Os isotope disequilibrium (Suzuki et al., 1990), ${ }^{3)}$ which remained unfading in spite of a variety of trials. This phenomenon was checked again, using commercially available $\mathrm{MoS}_{2}$ powder, which has been found originally to contain radiogenic ${ }^{187} \mathrm{Os}$ only and must have been prepared by mere pulverization of natural $\mathrm{MoS}_{2}$, in place of "natural" sample whose locality is known. During the distillation after processings of decomposition and dissolution, the measured ${ }^{187} \mathrm{Os} /{ }^{192} \mathrm{Os}$ ratio increased steadily from 0.75 to 1.65 in five hours, while the absolute ion intensity decreased rather rapidly with the time. (These tendencies are similar to those observed previously.) Based on these ratios and ion intensities, one can calculate by integration the Os concentration (see Fig. 1) in the $\mathrm{MoS}_{2}$ powder studied. It can be seen that the Os concentration evaluated approaches a certain level.

In order to attain perfect isotopic equilibrium, however, the third method employing the microwave digester was investigated, and, after many trials, we succeeded in establishing the optimum condition. When the molybdenite powder described above is treated following the microwave digestion procedure (for details, see below), the ${ }^{187} \mathrm{Os} /{ }^{192} \mathrm{Os}$ ratio does not change with progress in time of distillation, but is constant within experimental errors. Another important result is that the Os concentration evaluated from this constant ratio is re-

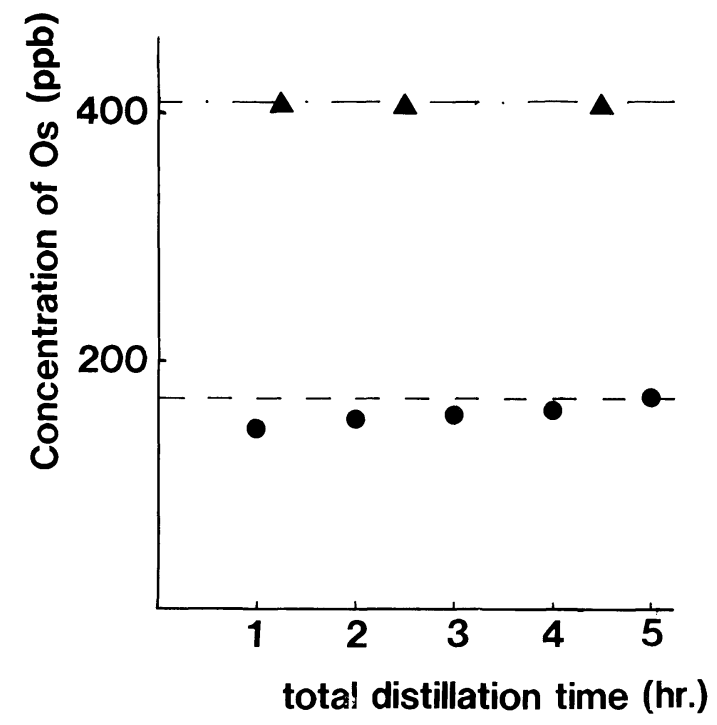

Fig. 1. Change of $\mathrm{Os}$ concentration calculated from the integrated ${ }^{187} \mathrm{Os} /{ }^{192} \mathrm{Os}$ ratio with the distillation time. Solid circles refer to the values obtained from the conventional closed-ampoule acid decomposition, while solid triangles to those from the treatment involving microwave digestion. 


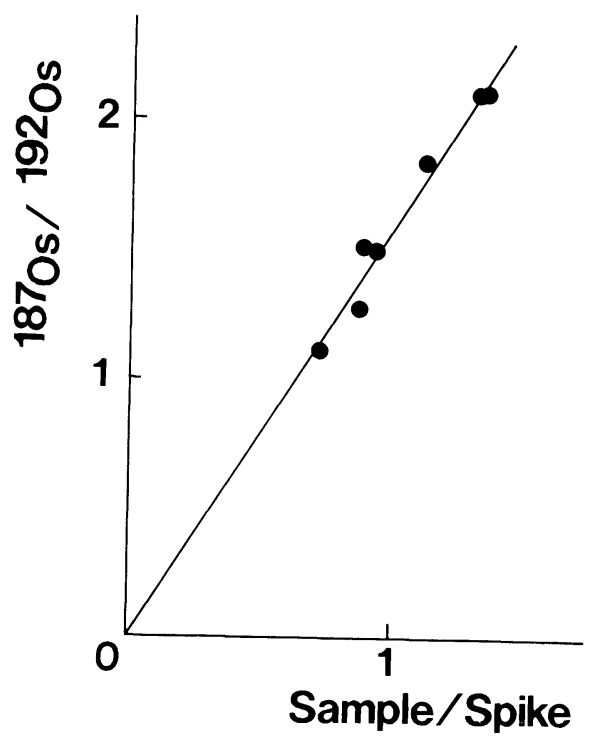

Fig. 2. Relationship between the observed ${ }^{187} \mathrm{Os} /{ }^{192} \mathrm{Os}$ ratio and the weight ratio of $\mathrm{MoS}_{2}$ to "spike" solution containing $630 \mathrm{ppb}$ common $\mathrm{Os} ; \mathrm{MoS}_{2}$ contains only ${ }^{187} \mathrm{Os}$ (radiogenic).

markably higher than that evaluated from integration of measurements obtained for the closed-ampoule acid decomposition (see Fig. 1). These empirical results strongly suggest that considerable amounts of radiogenic Os remain trapped in the polymerized molybdic acid in case of decomposition without the use of microwave digester.

To examine the reproducibility of this technique, ratios ${ }^{18 i} \mathrm{Os} /{ }^{192} \mathrm{Os}$ of the "spiked" sample were measured with the various sample/spike ratios. (Unlike the general cases, "spike" here is common Os.) The results are plotted in Fig. 2. The plotted points show a good correlation. As a result, the reproducibility is judged to be good.

Finally, we applied the new technique to two natural molybdenites whose ages of formation have been questionable. Luck and Allègre ${ }^{2)}$ reported 6370 and $6800 \mathrm{Ma}$ as Re-Os dates for molybdenite from Preissac, Canada, which are older than the earth. Our date $2700 \pm 90 \mathrm{Ma}$ as Re-Os age for this sample is in good agreement with $\mathrm{U}-\mathrm{Pb}$ age $(2680 \mathrm{Ma}){ }^{\left.{ }^{4}\right)}$ Meanwhile, as for district of Mätäsvaara, Finland, two different ages are reported; $2700 \mathrm{Ma}$ for zircon and $2400 \mathrm{Ma}$ for feldspar.5) The molybdenite age (1840 Ma) reported by Luck and Allègre $^{2 \prime}$ is much younger than either of two ages cited above. Our age (2300 \pm $80 \mathrm{Ma}$ ) obtained for Mätäsvaara molybdenite is in agreement with that for feldspar. These results indicate that our new technique is sufficiently dependable, overcoming the difficulty in Re-Os dating thus far.

The recommendable procedure is as follows. Molybdenite and the Os standard solution, "spike", are weighed and put into a vessel with a 1:1 mixture of concentrated $\mathrm{HNO}_{3}$ and $6 \mathrm{~N}_{2} \mathrm{SO}_{4}$. Then the vessel is put into the microwave digestion system, with magnetron frequency of $2450 \mathrm{MHz}$. We used the MDS-81D Microwave Digestion System, CEM Corporation. A vessel for the microwave digestion is made of teflon PFA. Since Os is absorbed on the sur- 
face of teflon resin, intensive cleaning is required for eliminating the Os "memory" on the vessel. Therefore, the sample should be decomposed in a closed glass ampoule in a teflon vessel if necessary.

To avoid superheating, the decomposition power in operation of the digester is controlled not to surpass $190 \mathrm{~W}$ even at the highest operation power. The vessel is heated for 5 minutes and cooled for 5 minutes, which cycle is repeated 5 to 10 times. And at first the vessel is warmed gently and then gradually heated up to the "highest" power. Total decomposition time is about 1 hour. After cooling the vessel, the decomposed solution is transferred into a distillation flask. Os is separated by distillation.

It is evident that the Os isotope equilibrium in question can be achieved by use of the microwave digestion method. The agitation or vibration on microscopic scale may facilitate the isotopic equilibrium of $\mathrm{Os}$ in presence of high concentration of Mo in aqueous solution. Anyway, the foregoing observations about isotopic disequilibrium and equilibrium are very interesting in relation with the characteristics of Os in molybdenum compounds. Further studies on this problem from the viewpoint of pure chemistry would be necessary.

Acknowledgments. We are grateful to Prof. K. Yamasaki, M. J. A. for his interest in this work. We are indebted to Mr. Qi Lu for access to the microwave digestion technique and to Dr. H. Shimizu for his helpful support. We also would like to express our gratitude to Drs. J. M. Franklin and I. R. Jonasson, Geological Survey of Canada, and Dr. O. Kouvo, Geological Survey of Finland, for donation of precious samples.

\section{References}

1) Lindner, M. et al. (1989): Geochim. et Cosmochim. Acta, 53, 1597-1606.

2) Luck, J. M., and Allègre, C. J. (1982) : Earth Planet Sci. Lett., 61, 291-296.

3) Suzuki, K., Shimizu, H., and Masuda, A. (1990): Abstract Issue, ICOG7, Canberra, Australia, p. 98.

4) Franklin, J. M., and Jonasson, I. R.: (personal communication).

5) Wetherill, G. W. et al. (1962): J. of Geology, 70, 74-87. 